\title{
Higher frequency dynamic response analysis of the foam concrete block element
}

\author{
Daniel Papán ${ }^{1, *}$, and Zuzana Papánová ${ }^{1}$ \\ ${ }^{1}$ University of Žilina, Faculty of Civil Engineering, Department of Structural Mechanics and Applied \\ Mathematics, Univerzitná 8215/1, 01026 Žilina, Slovakia
}

\begin{abstract}
In civil engineering structures frequency response are often low. There are some special tasks in innovative material parameters investigation where higher frequency response is important. The small dimension samples are often used to determinate material properties. This paper contains analysis of the natural modes and natural frequencies the foam concrete block sample.
\end{abstract}

\section{Introduction}

A new progressive modern materials are using in civil engineering more and more. One of this material is unconditionally the foam concrete. Many engineers and researchers are interesting in study of this material all over the world. The basic static and dynamic parameters are important to determinate for each mixture of basic foam concrete components. This paper shows how it is possible to determinate the basic dynamic parameters of simple shaped sample made from the foam concrete.

\section{Experimental object description}

The foam concrete block is really simple modelled type of sample. It has some special material properties and it has to be investigated. Small dimensional experiment on sample is effective to study higher frequency response of the dynamic behaviour. For this purpose, the experimental sample was casted into the mold with nominal dimension $10 \times 10 \times 40 \mathrm{~cm}$ (Figure 1). After several hours the overflowing part cuts off. The surface of wet concrete block is covered with foil. After 3 days the tested block freed from the mold and it is packed to the foil. All tests can be applied after 28 days from this process. The unit weight of the real investigated sample is measured and identified as $582 \mathrm{~kg} / \mathrm{m}^{3}$. Modulus of elasticity are $E_{\text {stat }}=521 \mathrm{MPa}$ and $E_{d y n}=611 \mathrm{Mpa}$. These parameters were obtained from standard material tests for material type FC500 - IWTECH. More detailed research about the foam concrete material and technical parameters is in $[1,2,3]$. The investigated sample is stiff fixed in first $10 \mathrm{~cm}$ on upper and down area to hard leaden block.

\footnotetext{
* Corresponding author: daniel.papan@,fstav.uniza.sk
} 


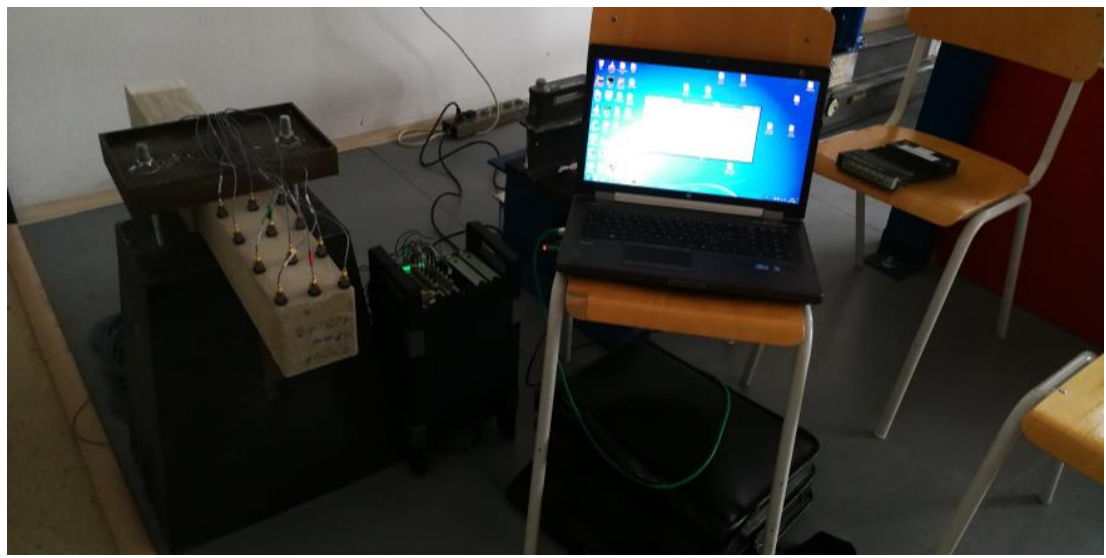

Fig. 1. The foam concrete with installed measurement equipment

\section{Measuring and evaluating system}

For the data recording were the powerful system PULSE used. PULSE is a versatile, taskoriented system for noise and vibration analysis. It provides the platform for a range of PCbased measurement solutions from Brüel \& Kjær. A PULSE system consists of a PC with LAN interface, PULSE software, Windows ${ }^{\circledR} 2000$, XP or Windows Vista ${ }^{\circledR}$, Microsoft ${ }^{\circledR}$ Office and idea - based data acquisition front-end hardware.

A system can contain more than 300 input channels located in up to 10 front-ends. The input/ output conditioning modules perform signal conditioning and digitalize the transducer signals. Measured line for the case study was created from parallel modules connected set and the others components, which are shown on Figure 2.

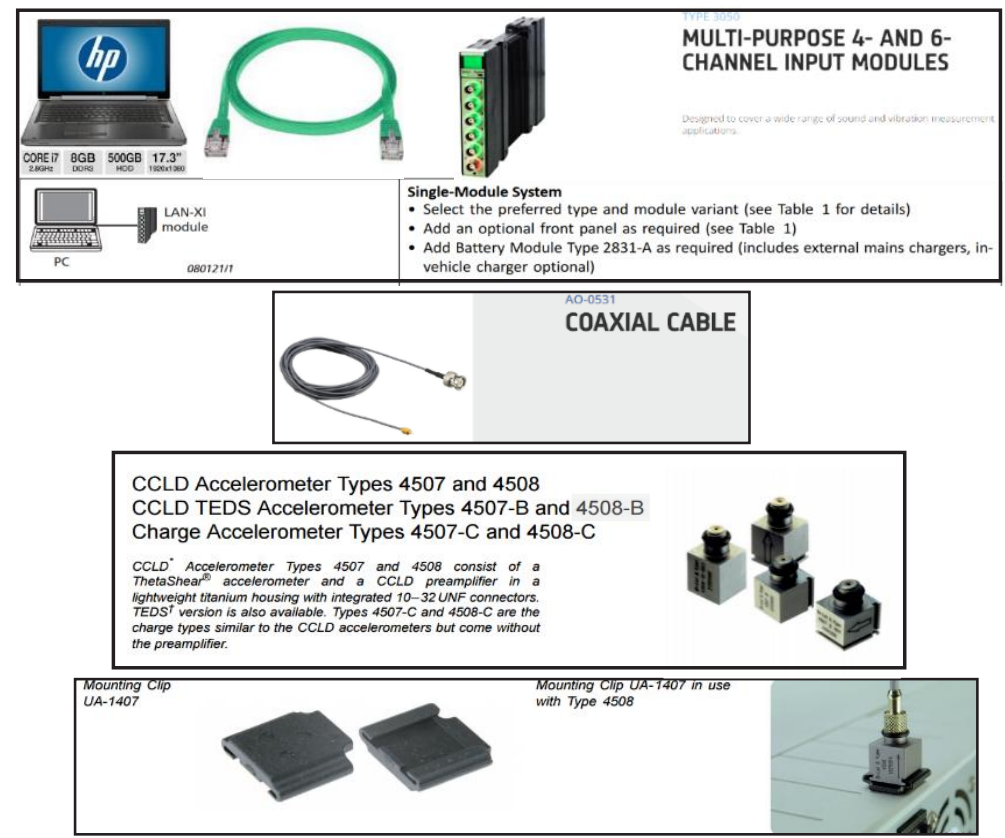

Fig. 2. Used measured tools Brüel \& Kjær with software PULSE included [4] 
ARTeMIS Modal is a software platform designed for Microsoft Windows 64-bit operating systems. To increase speed, it makes use of mathematical libraries from Intel. The help system is web based, so maximum performance is obtained by having an internet connection. Help system can be downloaded to the local computer if necessary. Signal processing of the measured data is applied with:

- Decimation, 1 - 1000 times, digital anti - aliasing filter, cut - off at 0.8 times Nyquist frequency of decimated signals

- Filtering: low - pass, high - pass, band - pass, bandstop Butterworth, filter order 1 - 50 poles, arbitrary cut - off frequencies, test for filter stability.

- Projection Channels. Specify if all cross information of the measurement channels should be used or only between fewer number of channels. Automatic detection of the required number of Projection Channels as well as what channels to pick. Specific channels can as option be selected explicitly

- Spectral estimation using FFT and Welch's averaged periodogram method. Data segment length: radix - 2 only limited by the amount of data, overlap: $66.7 \%$, window: Hanning. Estimates the full spectral matrix if the Projection Channel option is disabled.

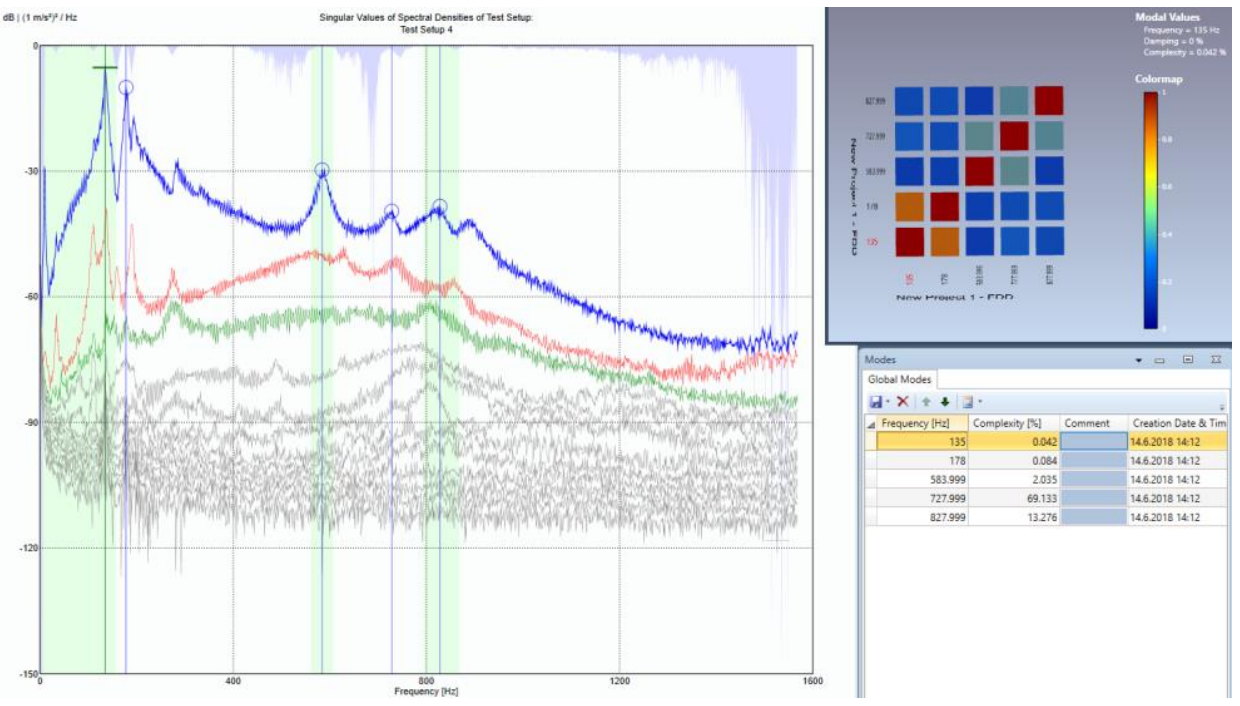

Fig. 3. ARTeMIS software processing example.

ARTeMIS Modal includes up to three frequency domain modal analysis techniques derived from the patented Frequency Domain Decomposition technology utilizing the singular value decomposition of the estimated spectral densities of the measured response. The techniques available are:

- Frequency Domain Decompostion - FDD.

- Enhanced Frequency Domain Decompostion - EFDD.

- Curve-fit Frequency Domain Decompostion - CFDD. [5]

\section{Numerical and experimental results}

Numerical model was created in VisualFEA system based on Finite Element Method (FEM). VisualFEA is integrated system for finite element analysis, which is an advanced numerical technique to solve and analyse physical problems arising in many fields of science and engineering. [6] FEM model of the sample respect all geometric, material and 
cinematic conditions of the real physical model. This model was described in capture 2 . The main observed dynamic parameters of the FEM model the natural modes and the natural frequencies were calculated. The results the dynamic of numerical calculation are in Figure 3.

\begin{tabular}{|l|c|}
\hline$f_{1}=138 \mathrm{~Hz}$ & $f_{6}=843 \mathrm{~Hz}$ \\
\hline$f_{2}=172 \mathrm{~Hz}$ & \\
\hline$f_{4}=783 \mathrm{~Hz}$ & $f_{7}=1453 \mathrm{~Hz}$ \\
\hline & \\
\hline & \\
\hline & \\
\hline & \\
\hline & \\
\hline
\end{tabular}




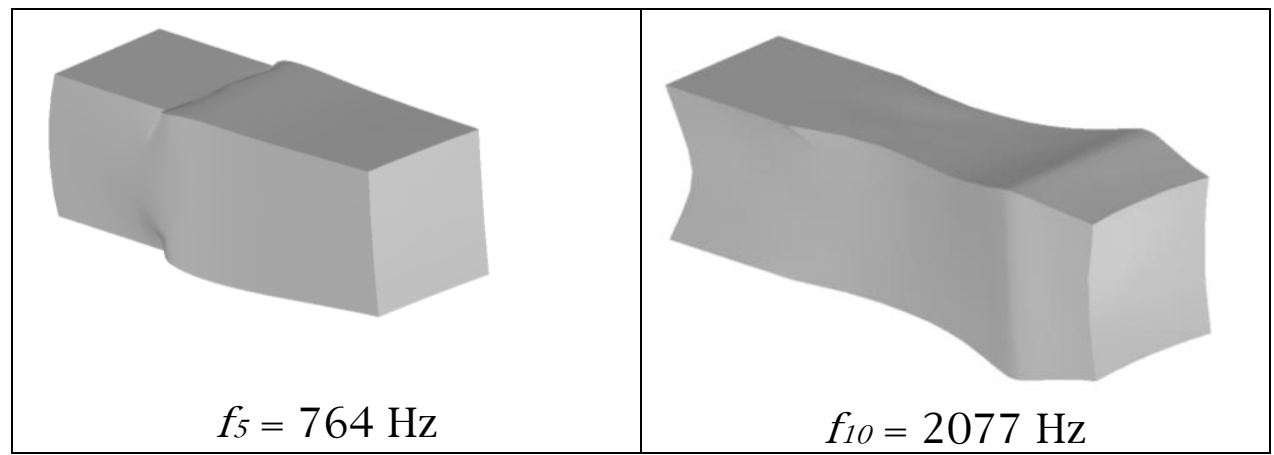

Fig. 4. Natural frequencies and natural modes FEM model obtained

For the experimental modal analysis was investigated upper area of the foam concrete block. The uniform grid 5x6cm with 12 Deltatron accelerometers type 4508 B 002 were installed on this area (Figure 1). Accelerometers were connected to two Input Module Type 3050-B-060 and the other PULSE compatible software and hardware accessories specified in chapter 2. The excitation was performed with a soft tapping all over the sample surface. Measured data were transformed to ARTeMIS system and processed using FDD. The relevant frequency broadband of the dynamic response is $100-900 \mathrm{~Hz}$ and resulted modes of natural vibration of the frame are presented in Figure 5. There is also MAC (Modal Assurance Criterion) values are also presented in bar graph on Figure 2 which indicates validation of the modal parameters.

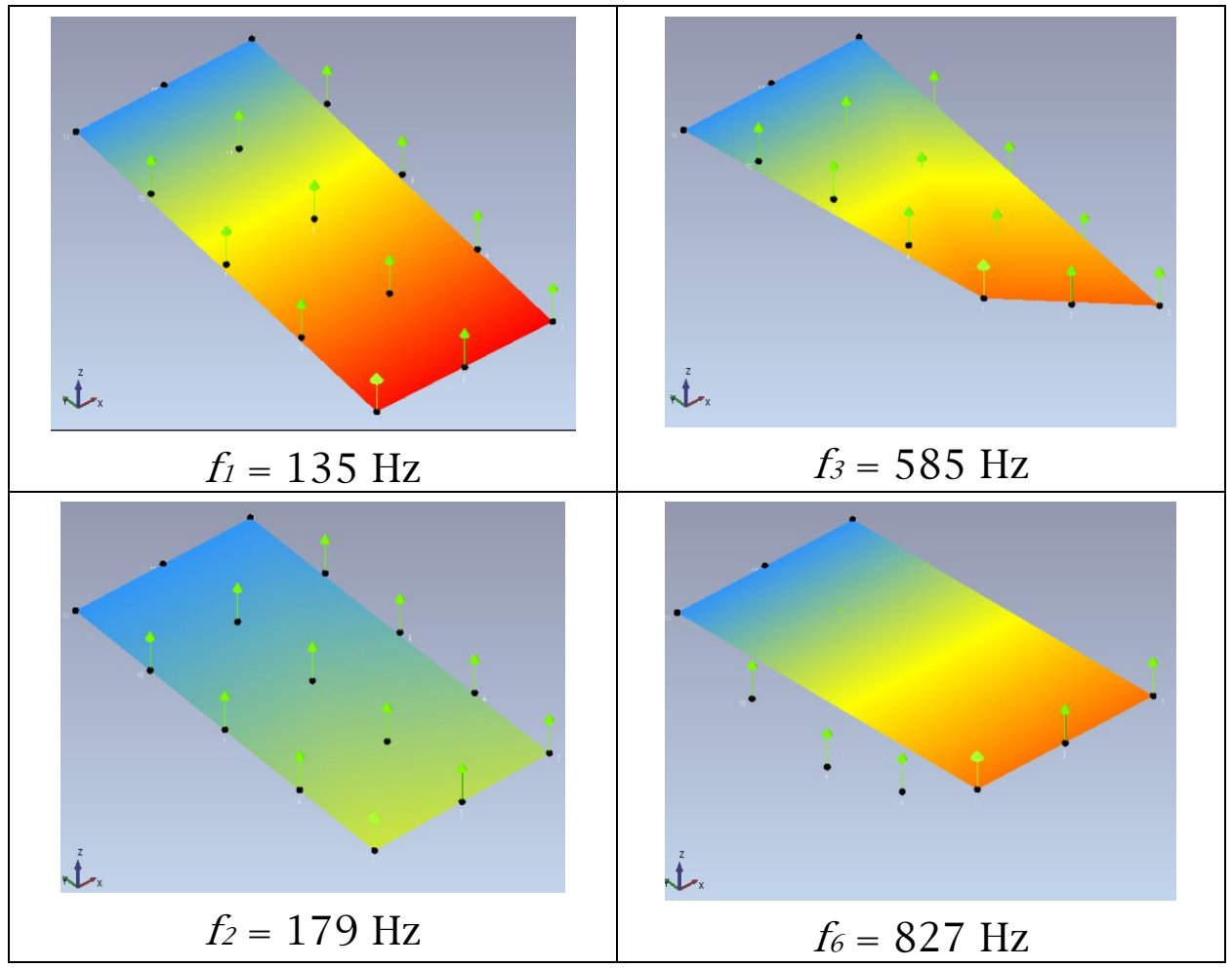

Fig. 5. Natural frequencies and natural modes experimental modal analysis obtained 


\section{Conclusions}

Investigation of the higher frequency response of the dynamic behaviour in laboratory conditions leads to following conclusions:

1. The foam concrete parameters identified in static analysis are close to the dynamic parameters in higher frequency bands.

2. Simple excitation can generate only a few natural mode shape. Maybe high frequency exciter can help to identify next natural modes.

3. Comparison of numerical and experimental is in good accordance which verify FEM model parameters.

4. Small differences $(\max 3 \%)$ in results - experimental versus numerical can be caused by not ideally stiff fixation of the foam concrete sample to the leaden block.

5. MAC values indicates relatively verified results of natural modes

This method can be used for identification of the basic dynamic parameters of the foam concrete material using small dimensional sample. This results manly verify material properties $E_{d y n}$ and $\rho$. All used for this paper - software and hardware equipment is property of University of Žilina.

\section{References}

1. M. Decký, M. Drusa, K. Zgútova, M. Blaško, M. Hájek, W. Scherfler, Procedia Engineering, 161, 428-433 (2016)

2. Vlček J. et al., IOP Conf. Series: Earth and Environmental Science, ISSN 1755-1315 (2017)

3. J. Vlček, K. Zgútová, D. Ďureková, Civil and environmental engineering - scientific technical journal, 11, 1, 38-44 (2015)

4. Electronic document: https://www.bksv.com/media/doc/bu0228.pdf

5. Electronic document:

http://www.svibs.com/Documents/ARTeMIS_Modal_Technical_Specs_ver5.pdf

6. Electronic document: http://www.visualfea.com/manual-normal/index_online.html 